\title{
UNINTENTIONAL HOUSEHOLD INJURIES AMONG CHILDREN UNDER TWELVE YEARS OF AGE, AND THEIR MOTHERS' HEALTH SEEKING BEHAVIOR: A CROSS SECTIONAL SURVEY CONDUCTED AT MILITARY HOSPITAL, RAWALPINDI
}

\author{
Humaira Mahmood', Saira Maroof', Sumaira Masood', Mahmood ur Rahman² \\ ${ }^{1}$ Assistant Professor, National University of Medical Sciences, Islamabad, PG Trainee, Health Services Academy, \\ Islamabad ( Com Med ), (Corresponding Author: humairatalha@hotmail.com), Demonstrator National University of \\ Medical Sciences, Islamabad( Com Med ), Demonstrator National University of Medical Sciences, Islamabad ( Com \\ Med), \\ ${ }^{2}$ Professor/HOD, Army Medical College ( Com Med )
}

\begin{abstract}
Background: Unintentional injuries among children cause a large burden of mortality and morbidity. Environmental factors play an important role in causing these injuries. The mortality rate from unintentional injuries in low income countries is nearly double than in the high income countries.

Objectives: To assess frequency of unintentional household injuries among children and mothers' health seeking behavior in different types of injuries.

Methods: It was a descriptive cross sectional study conducted in Military Hospital Rawalpindi from September 2015 to February 2016. A total of 116 mothers were interviewed having at least one child less than 12 years of age who has had sustained any household injury in last three months. A structured questionnaire was used for the study covering various aspects of the injury sustained and their health seeking behavior, after taking verbal consent from the participants. Collected data was analyzed using SPSS 22. Ap $<0.05$ was considered significant for a result.

Results: Of all the 116 participants, $68(58.6 \%)$ were males and $48(41.4 \%)$ were females with $36(31 \%)$ from rural and $80(69 \%)$ from urban area of residence. Mean age of the children was $5.74 \pm 2.78$. Most common injuries suffered in order of decreasing frequency were fall related injuries $48(41.4 \%)$, cuts/wound/bruises $41(35.3 \%)$, burns 18 $(15.5 \%)$,choking $8(6.9 \%)$ and poisoning $1(0.9 \%)$.Most of the injuries were sustained at evening time $44(37.9 \%)$ and mostly $78(67 \%)$ when the child was not accompanied by an adult.. As far as, management is concerned $48(41.4 \%)$ of the injuries were managed at home rest taken to some health facility.

Conclusion: The most common accidental household injuries were falls. Most of the injuries were managed at home adequately but in case of severe injuries mothers seek help from a hospital or nearby clinic.
\end{abstract}

Key words: Accidental household injuries, health seeking behavior, first aid

Introduction:

provincial health departments also regulate private health care providers. Large variations are found in public sector spending on health care across provinces. Private sector serves nearly 70 percent of the population. It is primarily a fee-for-service system and covers a range of health care provision from trained allopathic physicians to faith healers operating in the informal private sector .

Up till recently, except for the Pakistan Medical \& Dental Council (PM\&DC) and Pakistan Nursing Council (PNC) regulations there were no other regulations for the healthcare facilities in Pakistan. During the past three to five years, the Punjab and Sindh Healthcare Commission bodies have been formulated. The commissions have formulated local acts known as Punjab and Sindh Healthcare Commission Acts that have been approved by the Punjab and Sindh provincial assemblies and are in the process of implementation. The acts contain defined set of regulations for the healthcare facilities in Punjab and Sindh . The prime aim of these acts is to register all the healthcare facilities in Pakistan followed by licensing and accreditation processes. For the nuclear imaging facilities, the Pakistan Nuclear Regulatory Authority (PNRA) provide regulations for safe operations of these facilities in the country and also ensure licensing of these facilities. For regulating the use of blood and blood products, the Department of Health initiated a regulatory body with defined regulations to ensure safe blood and blood products transfusion services across the country.

\section{Objectives}

The objectives of the study were to determine the frequency of different household injuries among children under 12 years of age and environmental factors that might have played a role and to assess the health 
seeking behavior of the mothers in response to household injuries among these children.

\section{Methodology}

This descriptive cross-sectional study was conducted at outpatient departments of Military Hospital Rawalpindi over a period of 06 months from Aug 2015 to Jan2016. Sample size was calculated using WHO sample size calculator with anticipated population proportion of 0.18 , confidence interval $95 \%$ and precision $7 \%$. A total of 116 mother child pair was included in study using non probability consecutive sampling. Mothers' of those children who suffered any form of accidental household injury in last 3 months were interviewed. While children who were physically or mentally handicapped were excluded. A structured questionnaire was used to collect the data by interviewing the mothers after taking informed verbal consent. Demographic characteristics of the every child was noted and a detailed account of the injury was asked regarding its type, body part involved, how it was managed and source of knowledge regarding management of injury. Data was analyzed by using SPSS 22 . Qualitative variables were expressed by frequencies and percentages while means and standard deviations were calculated for quantitative variables. Chi square test of significance was used to determine the relationship between educational status of mothers and their health seeking behavior.

\section{Results}

A total of 116 mother-child pairs participated in the study, mean age of the children was $5.74 \pm 2.78$ years and mean age of mothers was $32 \pm 5.8$ years. Distribution of other demographic characteristics is given in table-1. Most common injuries suffered by $48(41.4 \%)$ children were falls while cuts and wounds by $41(35.3 \%)$, burns by $18(15.5 \%)$, choking by $8(6.9 \%)$ and poisoning by 1 $(0.9 \%)$ children depicted in fig-1. Most of these injuries i.e. $78(67 \%)$ occurred when the children were not accompanied by an adult. Injuries were encountered mostly in the afternoon and evening 85 (73.3\%) while 18 $(15.5 \%)$ in the morning and $13(11.2 \%)$ at night.

Table 1: Demographic characteristics of mothers and children

\begin{tabular}{|l|c|l|}
\hline \multirow{4}{*}{ Educational status } & CHARACTERISTICs & FREQUENCY (\%) \\
\cline { 2 - 3 } & Pecondary/ Higher Secondary & $42(36.2 \%)$ \\
\cline { 2 - 3 } & Bachelors/Master & $64(55.2 \%)$ \\
\hline Occupation & Housewife & \\
\cline { 2 - 3 } & Working & $97(83.6 \%)$ \\
\cline { 2 - 3 } & Place of residence & $19(16.4 \%)$ \\
\cline { 2 - 3 } & Urban & $80(69 \%)$ \\
\cline { 2 - 3 } & Rural & $36(31 \%)$ \\
\hline
\end{tabular}

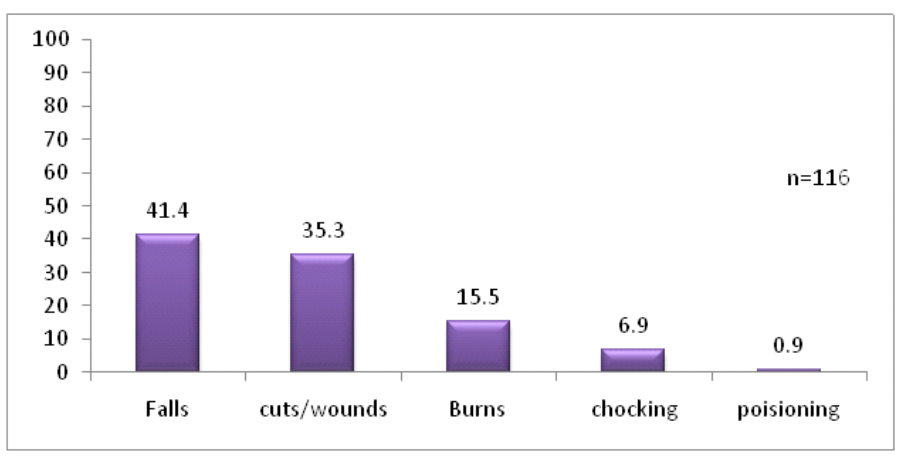

Fig 1.Frequcy of various unintentional accidental injuries in children

When inquired about the place of the accident it was told that $43(37 \%)$ occurred in bedroom, $32(28 \%)$ in balcony, $19(16 \%)$ at stairs, $16(14 \%)$ in the kitchen and $6(5 \%)$ in the bathroom. Most common part of the body involved was head and neck region in 40 (34\%), upper limb in 35 $(30 \%)$, lower limb in $28(24 \%)$, trunk in $3(3 \%)$ and other parts in $10(9 \%)$ of children.

The mothers were given various options about first aid management of accidental injuries faced by them; responses of the mothers have been given in table- 2 . After initial management at home, 48(41.4\%) didn't need any subsequent care, $47(40.5 \%)$ were taken to the hospital, $18(15.5 \%)$ to a nearby private clinic, 2 $(1.7 \%)$ to hakim and $1(0.9 \%)$ were taken to a quack. Of the $68(58.62 \%)$ children who were taken to health facility, only $12(17.6 \%)$ got hospitalized and 56 (82.4 $\%$ ) were adequately managed as outpatients. Among school going $51(57 \%)$ didn't get absent from school because of injury, $27(30 \%)$ remained absent for $1-3$ days, $5(5 \%)$ absent for $4-7$ days and 7 children (8\%) remained absent for more than a week.

\begin{tabular}{|c|c|c|}
\hline Type of injury & First aid provided by mothers & Frequency \\
\hline \multirow{5}{*}{$\begin{array}{l}\text { Fall related injuries } \\
\qquad(\mathrm{n}=48)\end{array}$} & $\begin{array}{l}\text { Cleaned and put dressing on fall } \\
\text { related wounds }\end{array}$ & $16(33.3 \%)$ \\
\hline & Left untreated & $14(29.2 \%$ \\
\hline & ann & $10(20.8 \%)$ \\
\hline & Cleaned wound and left open & $7(14.6 \%)$ \\
\hline & Put splint in case of fracture & $1(2.1 \%)$ \\
\hline \multirow{5}{*}{$\begin{array}{l}\text { Cuts/ wounds/ } \\
\text { bruises } \\
(n=41)\end{array}$} & Cleaned and applied dressing & $18(43.9 \%)$ \\
\hline & Cleaned and left open & $8(19.5 \%)$ \\
\hline & Others & $8(19.5 \%)$ \\
\hline & Left untreated & $5(12.2 \%)$ \\
\hline & Hot /cold fomentation & $2(4.9 \%)$ \\
\hline \multirow{5}{*}{$\begin{array}{l}\text { Burns } \\
(n=18)\end{array}$} & Applied an ointment and oil & $8(44 \%)$ \\
\hline & Removed child's clothing & $3(16.7 \%)$ \\
\hline & $\begin{array}{l}\text { Used ointment and removed child's } \\
\text { clothing }\end{array}$ & $3(16.7 \%)$ \\
\hline & Applied ice cold water & $2(11.1 \%)$ \\
\hline & Applied tooth paste & $2(11.1 \%)$ \\
\hline
\end{tabular}




\begin{tabular}{|c|l|c|}
\hline Type of injury & First aid provided by mothers & Frequency \\
\hline $\begin{array}{c}\text { Choking } \\
(\mathrm{n}=8)\end{array}$ & $\begin{array}{l}\text { Thumped the child on back to expel } \\
\text { the foreign body }\end{array}$ & $6(75 \%)$ \\
\cline { 2 - 4 } & $\begin{array}{l}\text { Inserted finger to pull out the } \\
\text { choking agent }\end{array}$ & $2(25 \%)$ \\
\hline $\begin{array}{c}\text { Poisoning with } \\
\text { syrups or tablets } \\
(\mathrm{n}=1)\end{array}$ & Immediately taken to hospital & $1(100 \%)$ \\
\hline \multicolumn{2}{|c|}{}
\end{tabular}

When respondents were asked about their opinion about causes of accidental home injuries, Most common causes according to them were allowing children to play unsupervised $84(72.4 \%)$, leaving electrical appliances unchecked $12(10.3 \%)$, staircase without railing $10(8.6 \%)$, free access to kitchen $8(6.9 \%)$ and keeping medication in access $2(1.7 \%)$ given in table-3.

\section{Table 3: Most common cause of unintentional} injuries

\begin{tabular}{|l|c|c|}
\hline Types of injuries & Frequency (n) & Percent (\%) \\
\hline $\begin{array}{l}\text { Allowing children to play } \\
\text { unsupervised }\end{array}$ & 84 & 72.4 \\
\hline $\begin{array}{l}\text { Leaving electrical appliances } \\
\text { unchecked }\end{array}$ & 12 & 10.3 \\
\hline Staircase without railing & 10 & 8.6 \\
\hline Kitchen -Free access & 8 & 6.9 \\
\hline Keeping medications in access & 2 & 1.7 \\
\hline Total & 116 & 100.0 \\
\hline
\end{tabular}

\section{Discussion}

The results of our study revealed that proportion of injuries for falls was highest $41.4 \%$ followed by cuts/wounds $35.3 \%$, and those findings were consistent with a study carried out in Egypt in which, falls was the most common (48\%) followed by cuts/wounds (36\%). Another study at the Aga Khan University, Karachi also showed similar results.

Most of unintentional injuries in our study occurred in children aged 3-6 years (44\%), similar to a study done in China . Most of the injuries occurred at home $(37 \%)$, mostly in boys $(68 \%)$ and in head/neck and musculoskeletal region( $88 \%$ ) . The results are in line with studies done in India , Egypt and Tanzania .

An interesting finding of the study was that more than three fourth $(83 \%)$ of the mothers of the children, who suffered unintentional injuries, were housewives. This finding commemorates another study's findings which shows that about $60 \%$ of the mothers were not working . In our study less than half $(42 \%)$ of the injuries were managed at home by applying different first aid measures. The rest $(68 \%)$ received ambulatory treatment at some health facility, and most of them were not hospitalized. These results go hand in hand with a study conducted in Turkey .

Common hazards recognized by mothers in our study were uncovered switch boards $(37.1 \%)$, knives in the easy reach of children (19\%), and drugs $(12 \%)$ similar to a study at Bristol .

Our study's limitations were that the data were collected regarding the past event from mothers, which might have introduced some recall bias. Further due to time constraint, our sampling frame and sampling size both were small and therefore the result may not be generalizable.

\section{Conclusion}

The most common injuries among children up to 12 years of age are falls cuts, wounds and burns. Boys sustain more injuries than the girls. Most of the injuries were managed at home adequately. But in case of severe injuries, mothers seek help from a nearby health facility

\section{Recommendations}

Health education programmes regarding cause of home accidents, methods of prevention, first aid management should be incorporated in the curriculum at different levels. Further, research on large scale should be carried out regarding accidental home injuries among children.

\section{References}

1. Atak N, Karaoglu L, Korkmaz Y, Usubütün S. A household survey: unintentional injury frequency and related factors among children under five years in Malatya. The Turkish journal of pediatrics. 2010;52(3):285.

2. Razzak JA, Kellermann AL. Emergency medical care in developing countries: is it worthwhile? Bulletin of the World Health Organization. 2002;80:900-5.

3. Odendaal W, Van Niekerk A, Jordaan E, Seedat M. The impact of a home visitation programme on household hazards associated with unintentional childhood injuries: a randomised controlled trial. Accident Analysis \& Prevention. 2009;41(1):18390.

4. Chandran A, Hyder AA, Peek-Asa C. The global burden of unintentional injuries and an agenda for progress. Epidemiologic reviews. 2010:mxq009.

5. Hyder AA, Sugerman DE, Puvanachandra $P$, Razzak J, El-Sayed H, Isaza A, et al. Global childhood unintentional injury surveillance in four cities in developing countries: a pilot study. Bulletin of the World Health Organization. 2009;87(5):34552. 
6. Morrongiello BA, Corbett M, Lasenby J, Johnston $\mathrm{N}$, McCourt M. Factors influencing young children's risk of unintentional injury: Parenting style and strategies for teaching about home safety. Journal of Applied Developmental Psychology. 2006;27(6):560-70.

7. Morrongiello BA, Klemencic N, Corbett $\mathrm{M}$. Interactions between child behavior patterns and parent supervision: Implications for children's risk of unintentional injury. Child development. 2008;79(3):627-38.

8. Lasi S, Rafique G, Peermohamed H. Childhood Injuries in Pakistan: Results from Two Communities. Journal of Health, Population and Nutrition. 2010;28(4):392-8.

9. Morrongiello BA, Dawber T. Toddlers' and mothers' behaviors in an injury-risk situation: Implications for sex differences in childhood injuries. Journal of Applied Developmental Psychology. 1998;19(4):625-39.

10. Klassen TP, MacKay JM, Moher D, Walker A, Jones $A L$. Community-based injury prevention interventions. The Future of Children. 2000:83-110.

11. Philippakis A, Hemenway D, Alexe DM, Dessypris $\mathrm{N}$, Spyridopoulos T, Petridou E. A quantification of preventable unintentional childhood injury mortality in the United States. Injury prevention. 2004;10(2):79-82.

12. sayed Bayomi S, Mobarak AA. Preschool Children Injuries in Rural and Urban Communities at Assiut Governorate: A Comparative Study. Journal of American Science. 2013;9(5).

13. Lasi S, Rafique G, Peermohamed H. Childhood injuries in Pakistan: results from two communities. Journal of Health, Population and Nutrition. 2010:392-8.

14. Fang Y, Zhang X, Chen W, Lin F, Yuan M, Geng Z, et al. Epidemiological characteristics and burden of childhood and adolescent injuries: a survey of elementary and secondary students in Xiamen, China. BMC public health. 2015;15(1):1.

15. Mahalakshmy T, Dongre AR, Kalaiselvan G. Epidemiology of childhood injuries in rural Puducherry, South India. The Indian Journal of Pediatrics. 2011;78(7):821-5.

16. Kamel EG, Emam SA, Mohammed ES. Knowledge, attitude and practice among rural mothers about Home-related injuries in a rural area in El-Minia Governorate, Egypt. Science. 2014;2(6):653-9.

17. Simon R, Gilyoma JM, Dass RM, Mchembe MD, Chalya PL. Paediatric injuries at Bugando Medical Centre in Northwestern Tanzania: a prospective review of 150 cases. Journal of trauma management \& outcomes. 2013;7(1):1.

18. Joshi MS, Stevens C. THE EFFECTIVENESS OF SAFETY EDUCATION AT ALERTING CHILDREN TO DAILY RISKS. 2014. 